\title{
The protective effect of curcumin against the 19-kDa Mycobacterium tuberculosis protein-induced inflammation and apoptosis in human macrophages
}

\author{
MINGYING LI ${ }^{1}$, ZHENXUAN WU ${ }^{1}$, WENYI NIU ${ }^{1}$, YONGGAN WAN ${ }^{1}$, \\ LIGONG ZHANG $^{2}$, GUANGCAN SHI ${ }^{2}$ and XIU'E XI ${ }^{1}$ \\ ${ }^{1}$ The Fourth Department of Tuberculosis; ${ }^{2}$ The Fifth Department of Tuberculosis, \\ The First Affiliated Hospital of Xinxiang Medical University, Xinxiang, Henan 453100, P.R. China
}

Received November 16, 2013; Accepted May 14, 2014

DOI: $10.3892 / \mathrm{mmr} .2014 .2615$

\begin{abstract}
The Mycobacterium tuberculosis 19-kDa lipoprotein (P19) is both cell wall-associated and secreted and is a candidate virulence factor that could cause the apoptosis of human macrophages infected with M. tuberculosis. P19 induces TLR2 activation, resulting in the upregulation of death receptors and ligands, followed by a death-receptor signaling cascade. The mechanisms by which P19 induces macrophage apoptosis are not fully characterized. Curcumin, a natural polyphenol, exhibits a variety of pharmacological effects such as antioxidant, anti-inflammatory and antitumor properties. In the present study, we investigated the effect of curcumin on P19-induced apoptosis in human macrophage cells and the underlying mechanisms. The results showed that both P19 and curcumin inhibit the growth of macrophages in a dose- and time-dependent manner. A low dose of curcumin $(10$ or $20 \mu \mathrm{M})$ attenuated both the macrophage cell growth inhibition and the increase in the expression of IL-6 and TNF- $\alpha$ induced by P19. Curcumin also decreased the phosphorylation of JNK and p38 that were induced by P19. However, JNK but not p38 inhibitors reversed the effect of P19 on the growth inhibition of macrophages. These data suggest that curcumin may protect macrophages from P19-induced cell apoptosis via a TLR2-mediated JNK-dependent pathway.
\end{abstract}

\section{Introduction}

The World Health Organization (WHO) estimates that one third of the population worldwide is infected with Mycobacterium tuberculosis, and that one tenth of the infected

Correspondence to: Dr Xiu'e Xi, The Fourth Department of Tuberculosis, The First Affiliated Hospital of Xinxiang Medical University, No. 88 Jiankang Road, Xinxiang, Henan 453100, P.R. China

E-mail: xiue_xi721@163.com

Key words: curcumin, Mycobacterium tuberculosis 19-kDa lipoprotein, macrophages, apoptosis, c-Jun N-terminal kinase population will develop active tuberculosis (1). Phagocytic cells, such as macrophages, dendritic cells (DCs) and neutrophils, are among the first cells to recognize M. tuberculosis within the host. Macrophages and DCs recognize M.tuberculosis by pattern recognition receptors (PRRs), such as toll-like receptors (TLRs) $(2,3)$. TLR2, 4 and 9 can mediate the in vitro recognition of $M$. tuberculosis. In their absence (particularly of TLR2), the cytokine response of macrophages or DCs to M.tuberculosis will be reduced (4-6). The apoptosis of macrophages in $M$. tuberculosis infection is considered to play an important role in the pathogenesis of tuberculosis. However, the mechanism underlying this apoptosis remains unclear.

Lipoproteins, which are post-translationally modified proteins, are generally considered to be potent immune modulators. Mycobacteria are rich in lipoproteins: there are $\sim 100$ open reading frames that possess the characteristic amino-terminal acylation motif of lipoproteins in the M. tuberculosis genome (7). The M.tuberculosis 19-kDa lipoprotein (P19) is cell wall-associated and immunodominant, and has been shown to stimulate the proliferation of $\mathrm{CD}^{+} \mathrm{T}$ cells and the release of interleukin 2 (IL-2), interferon- $\gamma$ (IFN- $\gamma$ ) and IL-12 $(8,9)$. In addition, P19 also acts as an adhesin, interacting with the mannose receptor, and promotes the phagocytosis of mycobacteria (10). Moreover, P19 plays a critical role in inducing the death of macrophages through both extrinsic (TLR2-dependent apoptotic pathway) and intrinsic (mitochondrial pathway) mechanisms (11).

Although the mechanism of apoptosis of mycobacteria-infected macrophages remains to be elucidated, it is clear that the activation of inflammation and apoptosis is involved in this process. Curcumin, a widely used dietary pigment and spice, possesses potent antioxidant, anti-inflammatory and antitumor activities $(12,13)$. Synthetic curcumin analogs and chalcone derivatives are considered as active compounds against $M$. tuberculosis, but their mechanism of action is not fully understood $(14,15)$. Curcumin can suppress cell growth by inhibiting various kinases, such as protein kinase $\mathrm{C}$ (PKC), c-Jun $\mathrm{NH}_{2}$-terminal kinase (JNK), and the epidermal growth factor (EGF) receptor kinase (16-18). Curcumin can also inhibit TLR2 gene expression and protein functions possibly via an oxidative process (19). Overall, the mechanism of the 
A

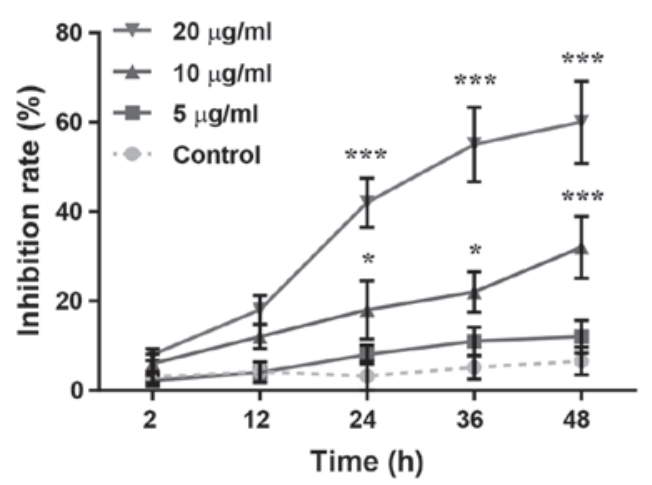

B

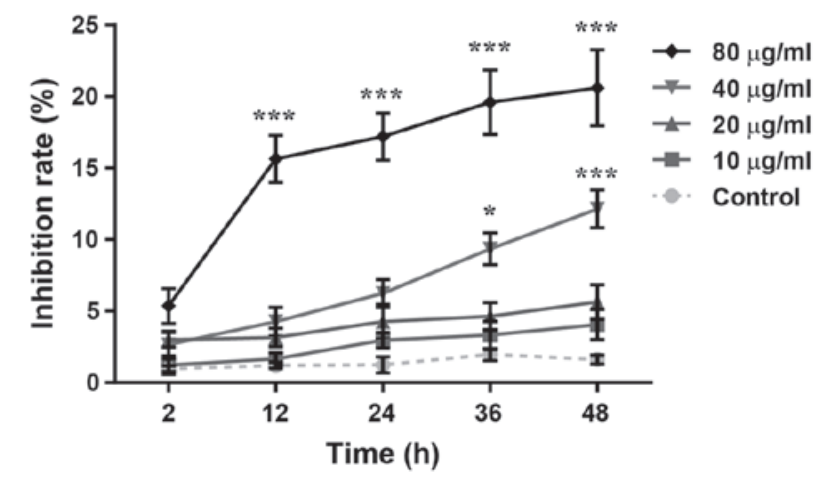

Figure 1. The 19-kDa lipoprotein (P19) and curcumin decrease the cell viability of WBC 264-9C macrophages. Cells were treated for 48 h with different concentrations of (A) Mycobacterium tuberculosis (M.tb)-derived P19 or (B) curcumin. The cell viability was measured by the MTT assay. Data are expressed as the mean $\pm \operatorname{SEM}(\mathrm{n}=3) .{ }^{*} \mathrm{P}<0.05,{ }^{* * *} \mathrm{P}<0.0001$, compared to the vehicle-treated (control) group.

anti-tuberculosis effect of curcumin remains unclear and needs to be further elucidated.

In the present study, we tested the hypothesis that curcumin exerts a protective effect against P19-induced inflammation and apoptosis in human macrophages by inhibiting the TLR2-induced and mitogen-activated protein kinase (MAPK)-dependent signaling pathways. Our results demonstrated that both P19 and curcumin induce the apoptosis of macrophages. Furthermore, our study indicated that low doses of curcumin can inhibit the apoptosis induced by P19 in macrophages by activating the JNK pathway.

\section{Materials and methods}

Reagents and antibodies. Curcumin was purchased from Sigma-Aldrich (St. Louis, MO, USA), was dissolved in dimethylsulfoxide (DMSO), and stored at $-20^{\circ} \mathrm{C}$. The final concentration of DMSO in all experiments was $<0.1 \%$. The JNK inhibitor SP600125 and the p38 inhibitor SB203580 were purchased from Cayman Chemical Co. (Ann Arbor, MI, USA). Cell culture reagents, medium, fetal bovine serum (FBS), L-glutamine, and antibiotics were purchased from Thermo Fisher Scientific (Gibco ${ }^{\circledR}$; Waltham, MA, USA). The antibodies targeting total extracellular signal-regulated kinase (ERK), phospho-ERK (Thr202/Tyr204), total JNK, phospho-JNK (Thr183/Tyr185), total p38, phospho-p38 (Thr180/Tyr182), TLR2 and GAPDH were purchased from Cell Signaling Technology (Danvers, MA, USA).

Bacterial strain and P19 isolation. The M. tuberculosis strain H37Rv was obtained from the American Type Culture Collection (ATCC 5618; Manassas, VA, USA) in lyophilized form, was reconstituted and used as previously described (20). M. tuberculosis 19-kDa lipoprotein (P19) was purified as previously described (21). Briefly, cell-wall fractions were obtained by sonication of resuspended M. tuberculosis H37Rv in icecold water (20 kHz, 5 cycles, 5 min each). Forty micrograms of protein were dissolved in a reducing sample buffer that contained $0.05 \mathrm{mM}$ EDTA, $0.1 \%$ sodium dodecyl sulfate (SDS), $1 \%$ glycerol, $10 \%$ 2-mercaptoethanol, and $0.5 \mathrm{mM} / \mathrm{ml}$ Tris- $\mathrm{HCl}$ (pH 6.8), were heated for $5 \mathrm{~min}$ at $95^{\circ} \mathrm{C}$ and were subjected to $12 \%$ SDS-polyacrylamide gel electrophoresis. Next, proteins

\section{M.tb-P19 + Curcumin}

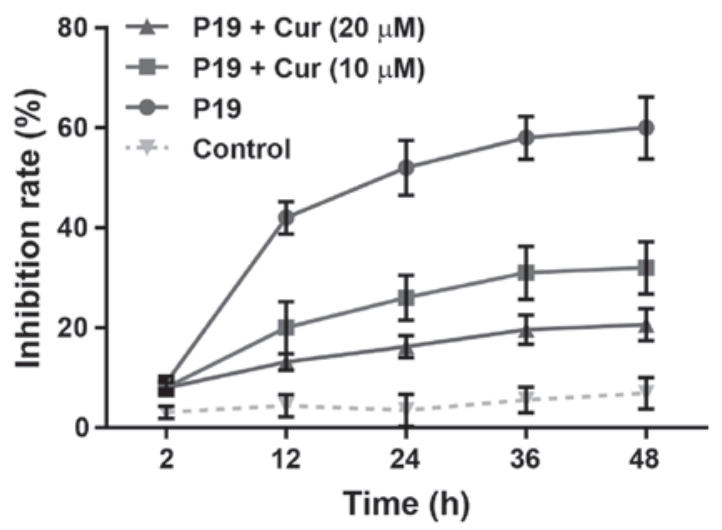

Figure 2. Low concentrations of curcumin (Cur) exert a protective effect against the 19-kDa lipoprotein (P19)-induced decrease in macrophage cell viability. Human WBC 264-9C macrophages were exposed to $20 \mu \mathrm{g} / \mathrm{ml}$ Mycobacterium tuberculosis (M.tb)-derived P19 alone or combined with 10 or $20 \mu \mathrm{M}$ curcumin for $48 \mathrm{~h}$. The cell viability was measured by the MTT assay. Data are expressed as the mean $\pm \operatorname{SEM}(n=3)$. Control, cells cultured in normal medium.

were transferred onto a nitrocellulose membrane and stained with Ponceau Red to identify the $19-\mathrm{kDa}$ band; this band was also identified using a rabbit monoclonal antibody IT-19 targeting the 19-kDA M. tuberculosis antigen (TB Research Material and Vaccine Testing Contract, Colarado State University, Colarado, USA). Then the band was excised, solubilized in DMSO and precipitated with a carbonate/bicarbonate sodium buffer (0.05 M, pH 9.6). The pellet was rinsed thrice with phosphate-buffered saline (PBS, $\mathrm{pH}$ 7.4) and stored at $-20^{\circ} \mathrm{C}$. The concentration of the protein was determined with the Bradford method (Bio-Rad, Hercules, USA).

Cell cultures. The WBC 264-9C macrophage line (ATCC HB-8902) was cultivated in RPMI-1640 medium supplemented with 15\% FBS, 10 mM HEPES (2-[4-(2-hydroxyethyl) piperazin-1-yl] ethanesulfonic acid), $2 \mathrm{mM}$ L-glutamine, and $50 \mu \mathrm{g} / \mathrm{ml}$ gentamicin, at $37^{\circ} \mathrm{C}$ in a humidified incubator containing 5\% $\mathrm{CO}_{2}$. For P19 treatment, WBC 264-9C cells were placed in 12-well plates with glass coverslips at a density 
A

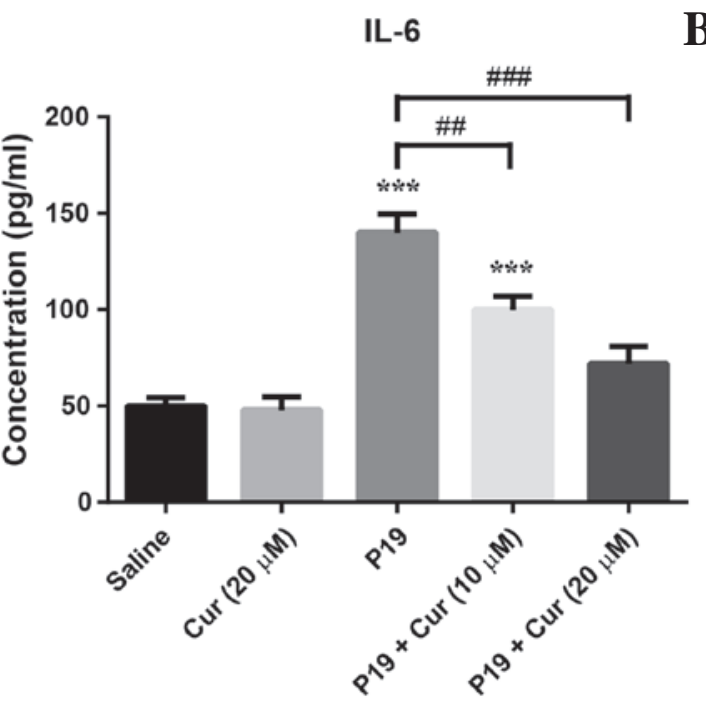

B

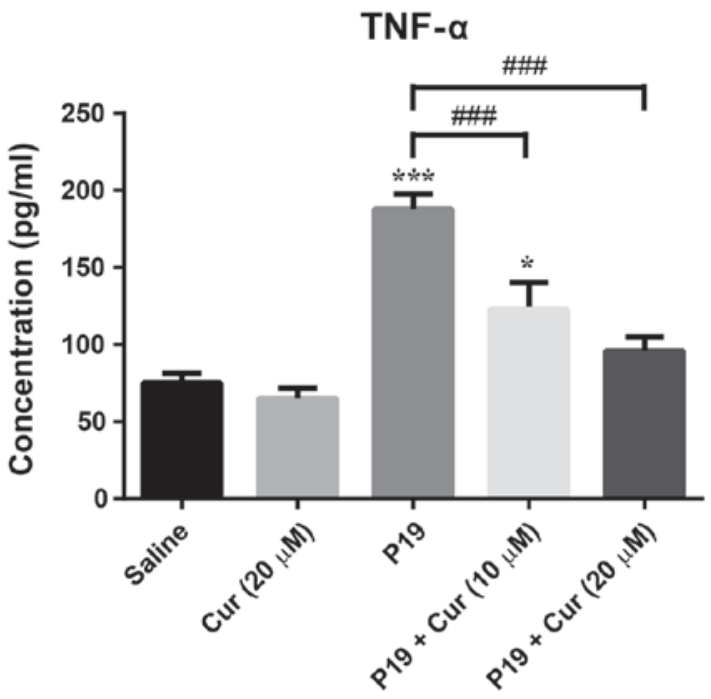

Figure 3. Curcumin (Cur) attenuates 19-kDa lipoprotein (P19)-induced cytokine production in the macrophages. Following treatment with $20 \mu \mathrm{g} / \mathrm{ml} \mathrm{P} 19$ alone or combined with 10 or $20 \mu \mathrm{M}$ curcumin for $48 \mathrm{~h}$, the levels of (A) interleukin 6 (IL-6) and (B) tumor necrosis factor- $\alpha$ (TNF- $\alpha$ ) were measured with the enzyme-linked immunosorbent assay. Data are expressed as the mean \pm SEM $(n=3) .{ }^{*} \mathrm{P}<0.05,{ }^{* * *} \mathrm{P}<0.0001$, compared to the saline-treated group; ${ }^{\# \#} \mathrm{P}<0.01$,

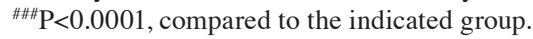

of $5 \times 10^{5}$ cells $/ \mathrm{ml}$ for $24 \mathrm{~h}$. Cells were then washed and incubated for an additional $18 \mathrm{~h}$ in the medium supplemented with $0.1 \%$ FBS. The macrophage monolayers in the tissue culture plates were washed with pre-warmed RPMI-1640 medium, which was then replaced with $1 \mathrm{ml}$ of RPMI-1640 medium supplemented with $10 \mathrm{mM}$ HEPES and $0.4 \%$ human serum albumin. The cells in the controls groups were cultured in the same RPMI-1640 medium and environmental conditions mentioned above, but were treated with $10 \%$ DMSO vehicles later.

Cell viability assays. The effect of P19 and curcumin on the viability of macrophages were evaluated using the MTT assay. Briefly, WBC 264-9C macrophages (1×104 cells/well) were seeded into a 96-well culture plate. Following adherence, the cells were treated with various concentrations of P19 $(5,10$ or $20 \mu \mathrm{g} / \mathrm{ml})$ or curcumin $(10,20,40$ and $80 \mu \mathrm{M})$, JNK inhibitor SP600125 $(30 \mu \mathrm{M})$ or p38 inhibitor SB203580P38 $(20 \mu \mathrm{M})$, and incubated at $37^{\circ} \mathrm{C}$ for various time periods. Then the medium was removed, and cells were incubated with $100 \mu \mathrm{l}$ $(0.5 \mathrm{mg} / \mathrm{ml})$ of 3-(4,5-dimethyl-2-thiazolyl)-2,5-diphenyl tetrazolium bromide (MTT; Sigma-Aldrich) for $4 \mathrm{~h}$ at $37^{\circ} \mathrm{C}$. The formazan crystals were solubilized with DMSO, and the absorbance was measured at $490 \mathrm{~nm}$ with a microplate reader (Tecan Trading AG, Männedorf, Switzerland).

Cytokine assays. The concentrations of IL-6 and tumor necrosis factor- $\alpha$ (TNF- $\alpha)$ in the supernatant of the cell cultures were determined by using Invitrogen ${ }^{\mathrm{TM}}$ enzyme-linked immunosorbent assay (ELISA) kits (Thermo Fisher Scientific) for the corresponding human proteins following the manufacturer's instructions.

Western blotting. Following treatment with P19 and/or curcumin, macrophages were rinsed with pre-warmed PBS and lysed in an ice-cold extraction buffer (50 mM Tris $\mathrm{pH} 7.5$, $150 \mathrm{mM} \mathrm{NaCl}, 10 \%$ glycerol, 1 mM EDTA, 1 mM EGTA, $1 \%$ NP-40, $1 \mathrm{mM}$ dithiothreitol, and a protease inhibitor cocktail). The homogenate was incubated on ice for $20 \mathrm{~min}$ and centrifuged at $13,000 \mathrm{x}$ g for $20 \mathrm{~min}$ at $4^{\circ} \mathrm{C}$. Next, the supernatant was collected, and the concentration of the protein in the supernatant was quantified using the Bradford method. The whole-cell lysate from the macrophages was subjected to $12 \%$ SDS-PAGE, and subsequently blotted onto a nitrocellulose membrane. The membrane was then incubated with the specific antibodies, using GAPDH as an internal control. Quantification of the protein bands was performed by densitometry using the QuantityOne software (Bio-Rad).

Statistical analysis. The data were expressed as mean \pm SEM from three independent experiments, and were analyzed using the SAS 8.2 software package (SAS Institute Inc., Cary, NC, USA). One-way analysis of variance (ANOVA) followed by Bonferroni correction was used to compare the means of three or more groups in the analyses of cell survival, cytokine production and protein expression. The phosphorylation levels of ERK, JNK and p38 were expressed as phosphorylated protein/total protein. $\mathrm{P}<0.05$ was considered to indicate statistically significant differences.

\section{Results}

P19 and curcumin decrease the cell viability of WBC 264-9C macrophages. The MTT assay was used to measure the viability of macrophages exposed to P19 or curcumin for 48 h (Fig. 1A). P19 inhibited the cell viability of WBC 264-9C macrophages in a concentration- and time-dependent manner $\left(\mathrm{F}_{\text {concentration }(3,100)}=55.0, \mathrm{P}<0.0001 ; \mathrm{F}_{\text {time }(4,100)}=18.6, \mathrm{P}<0.0001\right.$; $\left.\mathrm{F}_{\text {interaction }(12,100)}=4.87, \mathrm{P}<0.0001\right)$. Post-hoc analysis revealed that P19 significantly inhibits macrophage viability $(10 \mu \mathrm{g} / \mathrm{ml}$ inhibition rate, 32.4\%, $\mathrm{P}<0.0001 ; 20 \mu \mathrm{g} / \mathrm{ml}$ inhibition rate, $61.5 \%$, $\mathrm{P}<0.0001)$. Similarly, curcumin also inhibited macrophage viability (Fig. 1B) in an concentration- and time-dependent manner $\left(\mathrm{F}_{\text {concentration }(4,125)}=123, \mathrm{P}<0.0001 ; \mathrm{F}_{\text {time }(4,125)}=21.8\right.$, $\left.\mathrm{P}<0.0001 ; \mathrm{F}_{\text {interaction }(16,125)}=4.86, \mathrm{P}<0.0001\right)$. In WBC 264-9C 
A

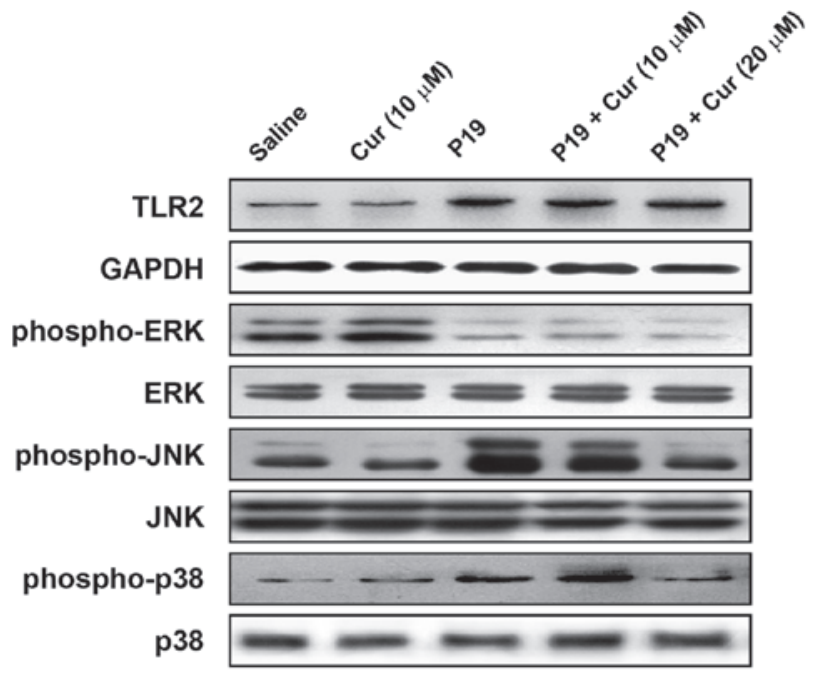

C

Phospho-ERK/ERK

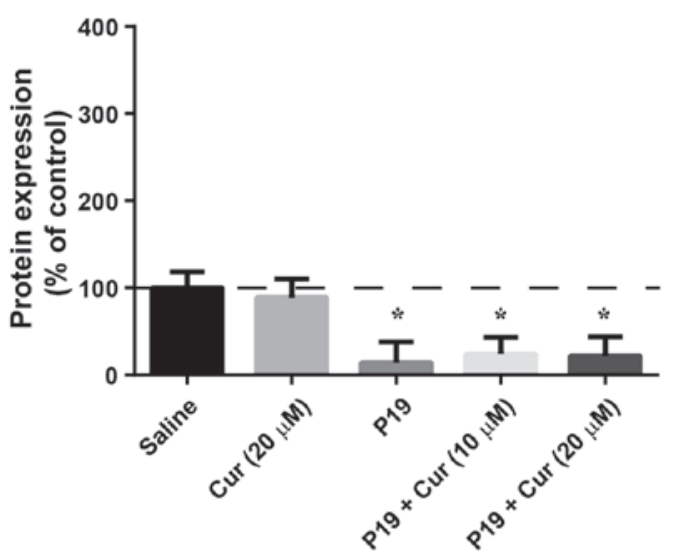

Phospho-p38/p38

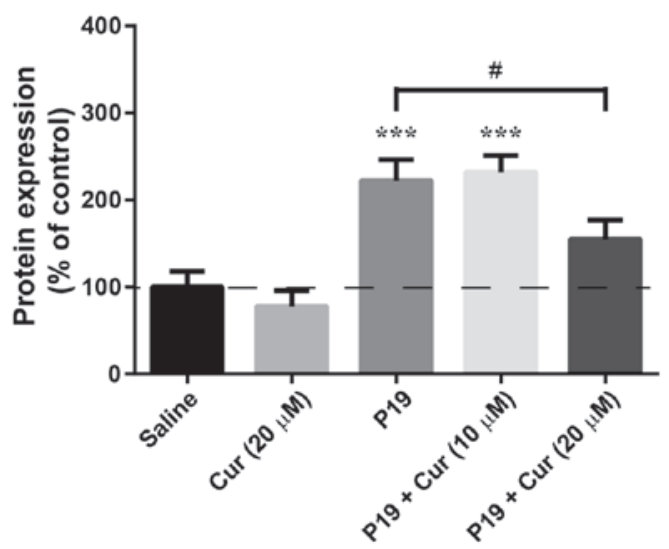

$\mathbf{E}$
B

TLR2

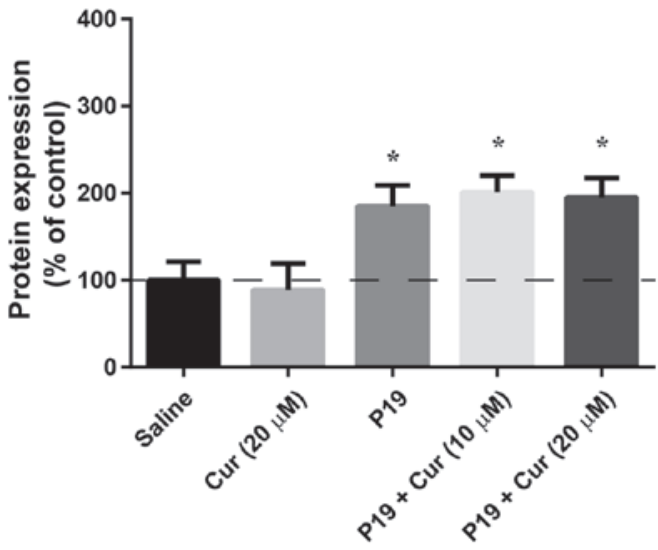

D

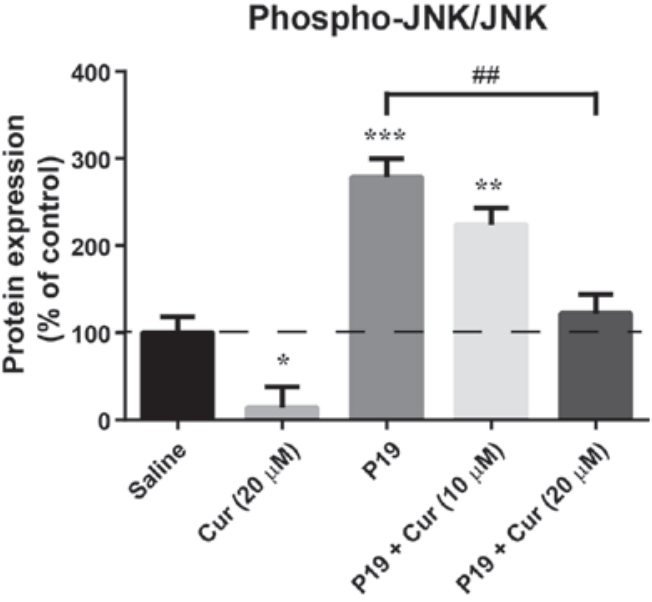

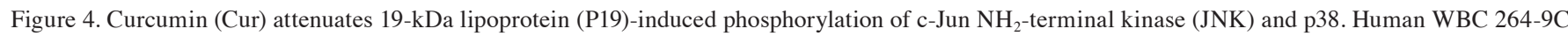
macrophages were exposed to vehicle (saline) treatment as a control, or $20 \mu \mathrm{g} / \mathrm{ml} \mathrm{P} 19$ treatment alone or combined with 10 or $20 \mu \mathrm{M}$ curcumin for $48 \mathrm{~h}$. (A) Representive western blots, with GAPDH serving as the loading control. (B) The protein level of TLR2 and the relative phosphorylation levels of (C) extracellular signal-regulated kinase $(E R K),(D) J N K$ and $(E)$ p38 were determined by densitometry analysis. Data are expressed as the mean \pm SEM ( $=3$ ). * $<<0.05$, ${ }^{* *} \mathrm{P}<0.01,{ }^{* * *} \mathrm{P}<0.0001$, compared to the saline-treated group; ${ }^{\#} \mathrm{P}<0.05,{ }^{\# \#} \mathrm{P}<0.01$, compared to the indicated group. TLR2, toll-like receptor 2 .

macrophages, high concentrations of curcumin resulted in $12.1-20.6 \%$ inhibition of cell viability $(40 \mu \mathrm{M}, \mathrm{P}<0.0001$ and $80 \mu \mathrm{M}, \mathrm{P}<0.0001$, respectively). However, low concentrations of curcumin (10 and $20 \mu \mathrm{M})$ did not cause a significant inhibition of cell viability. Therefore, $20 \mu \mathrm{g} / \mathrm{ml} \mathrm{P19}$, and 10 and $20 \mu \mathrm{M}$ curcumin were chosen for the following experiments. 
A

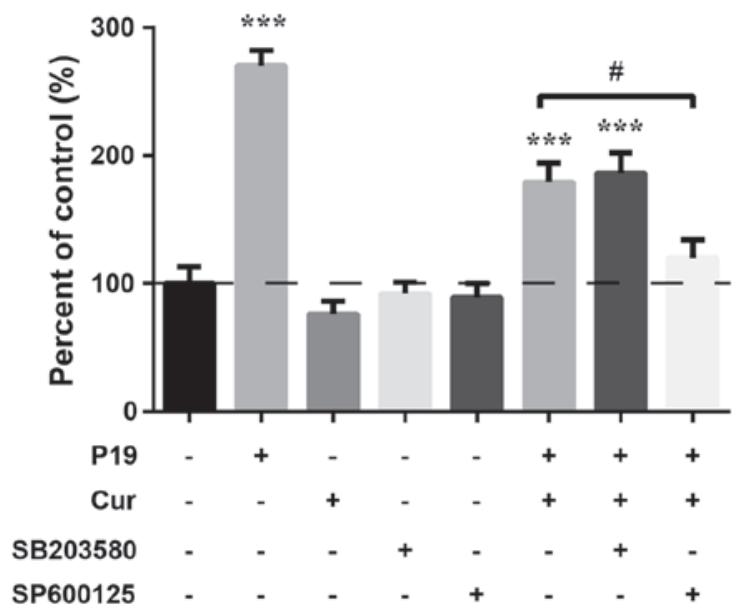

B

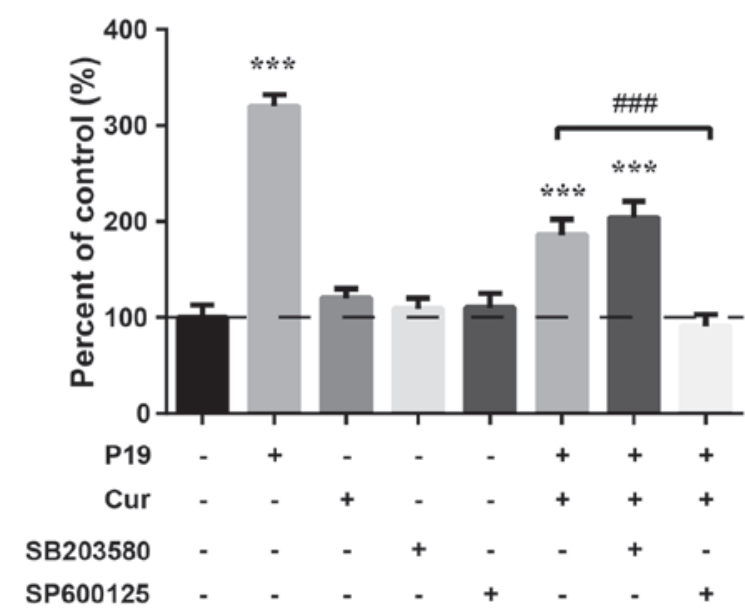

Figure 5. Pharmacological inhibition of c-Jun $\mathrm{NH}_{2}$-terminal kinase (JNK), but not p38, enhances the protective effect of curcumin (Cur) against 19-kDa lipoprotein (P19)-induced inflammatory responses. Human WBC 264-9C macrophages were treated for $1 \mathrm{~h}$ with and without the JNK inhibitor SB203580 $(20 \mu \mathrm{M})$ or the p38 inhibitor SP600125 $(30 \mu \mathrm{M})$ prior to treatment with $20 \mu \mathrm{g} / \mathrm{ml}$ P19 and/or $20 \mu \mathrm{M}$ curcumin for $48 \mathrm{~h}$. The levels of (A) interleukin 6 (IL-6) and (B) tumor necrosis factor- $\alpha(\mathrm{TNF}-\alpha)$ were measured with the enzyme-linked immunosorbent assay. Data are expressed as the mean $\pm \mathrm{SEM}(\mathrm{n}=3)$. ${ }^{* * *} \mathrm{P}<0.0001$, compared to the saline-treated (control) group. ${ }^{\#} \mathrm{P}<0.05$, ${ }^{\# \# \#} \mathrm{P}<0.0001$, compared to the indicated group.

Low concentrations of curcumin exert a protective effect against P19-induced inhibition of viability in macrophages. Human macrophages were exposed to vehicle (saline) treatment as a control, or to $20 \mu \mathrm{g} / \mathrm{ml} \mathrm{P19}$ alone or combined with 10 or $20 \mu \mathrm{M}$ curcumin for $48 \mathrm{~h}$. As expected, P19 treatment alone markedly reduced the cell viability $(58.7 \%, \mathrm{P}<0.0001)$ (Fig. 2). Notably, the combined treatment with P19 and a low concentration of curcumin $(10 \mu \mathrm{M})$ attenuated the inhibition of cell viability $(32.2 \%, \mathrm{P}<0.0001)$, compared to P19 treatment alone (Fig. 2). A higher concentration of curcumin $(20 \mu \mathrm{M})$ further decreased $(20.6 \%, \mathrm{P}<0.0001)$ the inhibition in cell viability induced by $\mathrm{P} 19$.

Curcumin attenuates P19-induced cytokine production in macrophages. ELISA was used to measure the IL-6 and TNF- $\alpha$ levels in the macrophages treated with $20 \mu \mathrm{g} / \mathrm{ml}$ P19 alone or combined with 10 or $20 \mu \mathrm{M}$ curcumin for $48 \mathrm{~h}$ (Fig. 3). The IL-6 and TNF- $\alpha$ levels were not significantly affected by treatment with $20 \mu \mathrm{M}$ curcumin alone. As expected, IL-6 and TNF- $\alpha$ levels were significantly elevated upon P19 treatment $(\mathrm{P}<0.0001)$, whereas the combination of $10 \mu \mathrm{M}$ curcumin and P19 significantly decreased the P19-induced IL-6 and TNF- $\alpha$ production (IL-6, $\mathrm{P}<0.01$; TNF- $\alpha, \mathrm{P}<0.0001$ ). Strikingly, treatment with $20 \mu \mathrm{M}$ curcumin completely offset the P19-induced cytokine production.

Curcumin attenuates P19-induced phosphorylation of JNK and $p 38$. To investigate the mechanism underlying the protective effects of curcumin against the P19-induced inflammatory responses, the expression of TLR2 and the phosphorylation of ERK, JNK and p38 were measured by western blot analysis (Fig. 4A). The expression of TLR2 did not significantly change following treatment with $20 \mu \mathrm{M}$ curcumin (Fig. 4B), whereas treatment with $20 \mu \mathrm{g} / \mathrm{ml}$ P19 significantly increased the TLR2 level $(\mathrm{P}<0.05)$. The $\mathrm{P} 19$-induced increase in the TLR2 level was not affected by cotreatment with 10 or $20 \mu \mathrm{M}$ curcumin.
As shown in Fig. 4, P19 decreased the phospho-ERK level $(\mathrm{P}<0.05)$, and increased the phospho-JNK $(\mathrm{P}<0.0001)$ and the phospho-p38 $(\mathrm{P}<0.0001)$ levels. Although treatment with $20 \mu \mathrm{M}$ curcumin alone had no significant effect on the p38 basal level, its phosphorylation was significantly decreased relative to treatment with $\mathrm{P} 19$ upon treatment with $20 \mu \mathrm{M}$ curcumin $(\mathrm{P}<0.05)$. Furthermore, the phosphorylation of JNK was decreased by both curcumin treatment alone $(\mathrm{P}<0.05)$ and when curcumin was combined with P19.

Pharmacological inhibition of JNK, but not p38, enhances the protective effect of curcumin against P19-induced inflammatory responses. To determine the role of JNK and p38 phosphorylation in P19-induced inflammatory responses, we pre-treated the macrophages with $20 \mu \mathrm{M}$ SP600125 (the JNK-specific inhibitor) or $30 \mu \mathrm{M}$ SB203580 (the $\mathrm{p} 38$-specific inhibitor) for $1 \mathrm{~h}$ prior to treatment with $20 \mu \mathrm{M}$ curcumin and $20 \mu \mathrm{g} / \mathrm{ml}$ P19. Cytokine production was determined by ELISA. Fig. 5 shows that treatment with the JNK inhibitor significantly decreased IL-6 $(\mathrm{P}<0.05)$ and TNF- $\alpha(\mathrm{P}<0.01)$ levels, compared to the combination of curcumin and P19. IL- 6 and TNF- $\alpha$ levels were slightly reduced after treatment with the p38 inhibitor, but the difference was not significant. These results demonstrated that activation of JNK, but not p38, may play a role in the protective effect of curcumin against P19-induced inflammatory responses.

\section{Discussion}

P19 plays an important role in the apoptosis of macrophages during $M$. tuberculosis infection. Induction of macrophage apoptosis by $M$. tuberculosis and thus, evasion from host defense, has been proposed as one of the mechanisms promoting M. tuberculosis virulence. Recently, the contribution of P19 in human $M$. tuberculosis infections received increasing attention. Elucidating the mechanism underlying P19-induced macrophage death during M. tuberculosis infections is important for the development of new anti-tuberculosis strategies. 
Furthermore, polyphenols such as curcumin possess numerous desirable qualities for anti-tuberculosis therapy.

Synthetic bacterial lipoproteins have been reported to induce macrophage apoptosis through TLR2, which implies that the mycobacterial 19-kDa lipoprotein (P19) may be a M. tuberculosis apoptosis-inducing factor. P19 is an abundantly expressed, cell wall-associated and secreted glycolipoprotein, with a highly conserved six-residue consensus sequence for lipidation adjacent to the hydrophobic signal peptide. Lopez et al showed that P19 induces apoptosis in the human monocytic cell line THP-1 and in human monocyte-derived macrophages (22). Consistently, our data showed that P19 induces the apoptosis of macrophages in a time- and dose-dependent manner. The apoptosis-inducing effect of P19 may be TLR2-dependent, since pre-treatment with blocking anti-TLR2 antibody was previously shown to inhibit the P19-induced apoptosis in THP-1 cells or TLR2-expressing Chinese hamster ovary cells (22). Recently, Sanchez et al revealed a novel mechanism for the M. tuberculosis-induced death of macrophages, whereby P19 triggers an intrinsic or mitochondrial pathway, associated with cytochrome $C$ and the apoptosis-inducing mitochondrial factor (11). Overall, P19 may induce macrophage apoptosis.

Curcumin has been known to inhibit the proliferation and/or induce cell death in a number of human cancer cell lines (23-27). Interestingly, curcumin is non-cytotoxic to healthy cells, and its pharmacological safety is well demonstrated by the fact that people in certain countries have consumed curcumin as a dietary spice for centuries in amounts exceeding $10 \mathrm{mg} /$ day without any side-effects (28). The present study provided evidence that curcumin can induce the death of macrophages in a dose- and time-dependent manner. Although the fact that curcumin induces apoptosis is well established, the exact mechanism underlying this effect is not yet fully elucidated. Potential mechanisms of curcumin-induced apoptosis include inhibition of various protein kinases such as PKC, JNK, and the EGF receptor kinase. Curcumin can also activate apoptotic pathways, such as p53-mediated apoptosis, in human basal cell carcinoma cells under stress conditions (29). Mitochondrial dysfunction triggered by enhanced Bax expression is also involved in curcumin-induced apoptosis $(30,31)$. Moreover, curcumin can block the nuclear factor- $\kappa \mathrm{B}(\mathrm{NF}-\kappa \mathrm{B})$ cell survival pathway $(32,33)$. However, the mechanism underlying curcumin-induced apoptosis has been mainly revealed from tumor cell lines, whereas the mechanism underlying curcumininduced apoptosis in macrophages still remains unclear.

We found that low concentrations of curcumin (10 and $20 \mu \mathrm{M}$ ) exert a protective effect against P19-induced apoptosis in macrophages, and attenuate P19-induced cytokine production. The protective effect may be mediated by JNK inhibition, since JNK, but not p38 inhibitors enhanced the protective effect of curcumin. Although additional data are needed to clarify the protective effect of curcumin against P19-induced apoptosis, we can conclude that curcumin and P19 may play opposing roles in inducing macrophage apoptosis. TLR2 receptor-induced JNK activation is one of the candidate signaling pathways involved in P19-induced apoptosis. In human monocytes and neutrophils, curcumin treatment decreased the gene expression of TLR2 and impaired the function of the protein (19). By contrast, P19 was shown to induce TLR2 activation, followed by JNK activation $(11,34)$.
In summary, we demonstrated that both P19 and high doses of curcumin can decrease the viability of human macrophages. Low doses of curcumin reduce the P19-induced apoptosis and the increased cytokine levels in the macrophages. The protective effect of curcumin may be attributed to its ability to block the TLR2-mediated JNK activation induced by P19. Our study has shed some light on the mechanism underlying the protective effect of curcumin against P19-induced macrophage apoptosis, and suggests that curcumin may be used as a therapeutic agent for the treatment of tuberculosis.

\section{References}

1. Dye C, Scheele S, Dolin P, Pathania V and Raviglione MC: Consensus statement. Global burden of tuberculosis: estimated incidence, prevalence, and mortality by country. WHO Global Surveillance and Monitoring Project. JAMA 282: 677-686, 1999.

2. Bhatt $K$ and Salgame P: Host innate immune response to Mycobacterium tuberculosis. J Clin Immunol 27: 347-362, 2007.

3. Akira S, Uematsu S and Takeuchi O: Pathogen recognition and innate immunity. Cell 124: 783-801, 2006.

4. Underhill DM, Ozinsky A, Smith KD and Aderem A: Toll-like receptor-2 mediates mycobacteria-induced proinflammatory signaling in macrophages. Proc Natl Acad Sci USA 96: 14459-14463, 1999.

5. Quesniaux V, Fremond C, Jacobs M, et al: Toll-like receptor pathways in the immune responses to mycobacteria. Microbes Infect 6: 946-959, 2004.

6. Holscher C, Reiling N, Schaible UE, et al: Containment of aerogenic Mycobacterium tuberculosis infection in mice does not require MyD88 adaptor function for TLR2, -4 and -9. Eur J Immunol 38: 680-694, 2008.

7. Cole ST, Brosch R, Parkhill J, et al: Deciphering the biology of Mycobacterium tuberculosis from the complete genome sequence. Nature 393: 537-544, 1998.

8. Boom WH, Husson RN, Young RA, David JR and Piessens WF: In vivo and in vitro characterization of murine T-cell clones reactive to Mycobacterium tuberculosis. Infect Immun 55: 2223-2229, 1987.

9. Brightbill HD, Libraty DH, Krutzik SR, et al: Host defense mechanisms triggered by microbial lipoproteins through toll-like receptors. Science 285: 732-736, 1999.

10. Diaz-Silvestre H, Espinosa-Cueto P, Sanchez-Gonzalez A, et al: The 19-kDa antigen of Mycobacterium tuberculosis is a major adhesin that binds the mannose receptor of THP-1 monocytic cells and promotes phagocytosis of mycobacteria. Microb Pathog 39: 97-107, 2005.

11. Sanchez A, Espinosa P, Garcia T and Mancilla R: The 19 kDa Mycobacterium tuberculosis lipoprotein $(\mathrm{LpqH})$ induces macrophage apoptosis through extrinsic and intrinsic pathways: a role for the mitochondrial apoptosis-inducing factor. Clin Dev Immunol 2012: 950503, 2012.

12. Kuo ML, Huang TS and Lin JK: Curcumin, an antioxidant and anti-tumor promoter, induces apoptosis in human leukemia cells. Biochim Biophys Acta 1317: 95-100, 1996.

13. Goel A, Kunnumakkara AB and Aggarwal BB: Curcumin as 'Curecumin': from kitchen to clinic. Biochem Pharmacol 75: 787-809, 2008.

14. Marathe SA, Dasgupta I, Gnanadhas DP and Chakravortty D: Multifaceted roles of curcumin: two sides of a coin! Expert Opin Biol Ther 11: 1485-1499, 2011.

15. Bukhari SN, Franzblau SG, Jantan I and Jasamai M: Current prospects of synthetic curcumin analogs and chalcone derivatives against Mycobacterium tuberculosis. Med Chem 9: 897-903, 2013.

16. Kawamori T, Lubet R, Steele VE, et al: Chemopreventive effect of curcumin, a naturally occurring anti-inflammatory agent, during the promotion/progression stages of colon cancer. Cancer Res 59: 597-601, 1999.

17. Lu YP, Chang RL, Lou YR, et al: Effect of curcumin on 12-O-tetradecanoylphorbol-13-acetate- and ultraviolet $\mathrm{B}$ light-induced expression of c-Jun and c-Fos in JB6 cells and in mouse epidermis. Carcinogenesis 15: 2363-2370, 1994.

18. Azuine MA and Bhide SV: Chemopreventive effect of turmeric against stomach and skin tumors induced by chemical carcinogens in Swiss mice. Nutr Cancer 17: 77-83, 1992. 
19. Shuto T, Ono T, Ohira Y, et al: Curcumin decreases toll-like receptor-2 gene expression and function in human monocytes and neutrophils. Biochem Biophys Res Commun 398: 647-652, 2010.

20. Schlesinger LS, Bellinger-kawahara CG, Payne NR and Horwitz MA: Phagocytosis of Mycobacterium tuberculosis is mediated by human monocyte complement receptors and complement component-C3. J Immunol 144: 2771-2780, 1990.

21. Sanchez A, Espinosa P, Garcia T and Mancilla R: The $19 \mathrm{kDa}$ Mycobacterium tuberculosis lipoprotein $(\mathrm{LpqH})$ induces macrophage apoptosis through extrinsic and intrinsic pathways: a role for the mitochondrial apoptosis-inducing factor. Clin Dev Immunol 2012: 950503, 2012.

22. Lopez M, Sly LM, Luu Y, Young D, Cooper H and Reiner NE: The 19-kDa Mycobacterium tuberculosis protein induces macrophage apoptosis through toll-like receptor-2. J Immunol 170: 2409-2416, 2003.

23. Thangapazham RL, Sharma A and Maheshwari RK: Multiple molecular targets in cancer chemoprevention by curcumin AAPS J 8: E443-E449, 2006.

24. Singh RP and Agarwal R: Mechanisms of action of novel agents for prostate cancer chemoprevention. Endocr Relat Cancer 13: 751-778, 2006.

25. Salehi P, Makhoul G, Roy R, Malhotra M, Mood ZA and Daniel SJ: Curcumin loaded NIPAAM/VP/PEG-A nanoparticles: physicochemical and chemopreventive properties. J Biomater Sci Polym Ed 24: 574-588, 2013.
26. Lopez-Lazaro M: Anticancer and carcinogenic properties of curcumin: considerations for its clinical development as a cancer chemopreventive and chemotherapeutic agent. Mol Nutr Food Res 52 (Suppl 1): S103-S127, 2008.

27. Campbell FC and Collett GP: Chemopreventive properties of curcumin. Future Oncol 1: 405-414, 2005.

28. Ammon HP and Wahl MA: Pharmacology of Curcuma longa. Planta Med 57: 1-7, 1991

29. Jee SH, Shen SC, Tseng CR, Chiu HC and Kuo ML: Curcumin induces a 53 -dependent apoptosis in human basal cell carcinoma cells. J Invest Dermatol 111: 656-661, 1998.

30. Uddin S, Hussain AR, Manogaran PS, et al: Curcumin suppresses growth and induces apoptosis in primary effusion lymphoma. Oncogene 24: 7022-7030, 2005.

31. Sen S, Sharma H and Singh N: Curcumin enhances Vinorelbine mediated apoptosis in NSCLC cells by the mitochondrial pathway. Biochem Biophys Res Commun 331: 1245-1252, 2005.

32. Singh S and Aggarwal BB: Activation of transcription factor NF-kappa B is suppressed by curcumin (diferuloylmethane) [corrected]. J Biol Chem 270: 24995-25000, 1995.

33. Bush JA, Cheung KJ Jr and Li G: Curcumin induces apoptosis in human melanoma cells through a Fas receptor/caspase-8 pathway independent of p53. Exp Cell Res 271: 305-314, 2001.

34. Watanabe I, Ichiki M, Shiratsuchi A and Nakanishi Y: TLR2-mediated survival of Staphylococcus aureus in macrophages: a novel bacterial strategy against host innate immunity. J Immunol 178: 4917-4925, 2007. 